\title{
Diagnosis and Pharmacological Management of Parkinson's Disease: A Review
}

\author{
Aiperi Almanbekova ${ }^{1}$ \\ ${ }^{1}$ Neurology Resident, Osh State University, Osh, Kyrgyzstan
}

DOI: https://doi.org/10.52403/ijhsr.20220215

\begin{abstract}
Parkinson's disease is a common and progressive neurological illness affecting persons aged 55 to 65 . Parkinson's disease (PD) is the second most common neurological disorder. It has the potential to result in considerable impairment and a low quality of life. However, symptomatic medications may assist patients in living more comfortably. Apart from distal resting tremor and stiffness, the condition manifests itself via bradykinesia and an asymmetric start. Progressive motor and non-motor symptoms have a detrimental effect on an individual's overall quality of life. Non-motor symptoms are increasingly gaining recognition. It might be difficult to treat both motor and non-motor complaints. As a result, primary care physicians should be capable of diagnosing and treating Parkinson's disease. The article examines various healthcare practitioners' diagnosis accuracy and their use of multiple diagnostic procedures to differentiate Parkinson's disease from other comparable illnesses. There is no cure for Parkinson's disease, although there are treatments. On the other hand, it examines non-motor symptoms of Parkinson's disease. Drug-induced dyskinesia is a side effect of levodopa, the primary Parkinson's disease medication. Treatment with a dopamine agonist initially alleviates motor problems. Alternative medications (monoamine oxidase type B inhibitors (MAOBIs), amantadine, anticholinergics, b-blockers, or dopamine agonists) may be provided first to avoid levodopa-related motor difficulties. Modifying the levodopa dosage or adding MAOBIs or dopamine agonists may assist in regulating motor fluctuations. Primary care doctors will benefit from this article's focus on early diagnosis and pharmaceutical treatment of Parkinson's disease's characteristic motor symptoms. Parkinson's disease-related motor symptoms may be treated with levodopa and dopamine agonists, according to several trials. No evidence exists to back up alternative treatments for motor or nonmotor symptoms. A subspecialist's opinion is often sought.
\end{abstract}

Keywords: Parkinson disease, tremor, levodopa, dopamine

\section{INTRODUCTION}

There is a high incidence of Parkinson's disease (PD) among adults between the ages of 55 and 65 [1]. Second only to Alzheimer's disease, Parkinson's disease (PD) is the most common neurological condition among the elderly. In 1817, James Parkinson was the first to use the name and describe the illness as it exists now. Substantial nigra degeneration, which affects movement and dopaminergic system regulation in people with Parkinson's disease, is one of its most prominent symptoms. Due to the loss of dopamine- producing cells, motor symptoms such bradykinesia and rigidity, as well as tremors and postural instability, proceed as a result $[4,5]$.

This disorder progresses slowly and gradually. Although these instances are rare and often sporadic, they have a reasonable familial incidence [3]. Although it was once believed to be a dopaminergic disorder, it is now recognized as a complex multisystem illness affecting both the motor and nonmotor systems of the body. The disease's progression may cause substantial disability, morbidity, and the requirement for nursing 
home care $[6,7]$. The loss of dopaminergic neurons in the substantia nigra, as well as the formation of eosinophilic intracytoplasmic inclusions (Lewy bodies) in the surviving dopaminergic neurons, are the neuropathologic characteristics of the disease. Dopaminergic neuron degeneration is a hallmark of the disease [8]. Parkinson's disease is a multisystem condition, and how a patient is diagnosed and treated early on may have a significant influence on their quality of life and quality of life for the rest of their life. In this article, the author talks about how they prefer to get a diagnosis and start treatment. They also point out some common mistakes and simple ways to communicate the diagnosis.

\section{Diagnosis and symptoms}

There are two main types of symptoms for people who have Parkinson's disease: motor and non-motor. People with both types of symptoms can be found, but not everyone has both types. Movement Disorders: The Society: A motor condition called Parkinsonism has three main symptoms: slow movement, rigidity, and tremor while you're sitting down [3]. These are three of the main signs of Parkinsonism. If a person has a motor manifestation, it usually starts in one place and lasts there longer than on the other [1].

Resting tremor, bradykinesia and slow movement are some of the symptoms [9]. They also have problems walking, talking and walking slowly, as well as muscle dystrophy and other problems with posture and stability. Pain, stiffness or numbness in limbs, slow movement, tremors, facial expression changes, and a drop in voice quality are some of the motor symptoms that show up in the early stages of this disease [1,9]. Late-stage motor features may include motor changes, dyskinesia, gait freezes, and falls, among other things. [4] Autonomic symptoms of non-motor include postural hypotension and drooling. These include sweating and dysarthrophonia. They also include nausea, constipation. Because motor symptoms have been the traditional way to tell if someone has PD, common non-motor symptoms have been under-reported and often not treated.

It is possible to make an initial diagnosis based on the patient's history and examination [10]. In advanced stages, nonmotor symptoms get more attention. They are present at all stages of PD [11,12]. Clinical history and examination are used to make a diagnosis of PD because there isn't a test for it [4]. While laboratory and radiological testing may be useful in excluding other probable causes, they have a very minor role. A 1--2-week trial of levodopa medication may be appropriate in certain individuals, and a favourable response may assist confirm the diagnosis [13]. Additionally, an acute levodopa challenge test may be performed to determine a patient's dopaminergic status. This is often done in patients who are already on medication. After an overnight fast and discontinuation of all dopaminergic medications, a single dosage of levodopa is administered in the morning. After then, the clinical response is followed for a few hours to see how well it is working. This test is an excellent predictor of a person's dopaminergic reactivity and provides important information about their response. Acute apomorphine challenge may also be attempted, however it is not as effective as levodopa [14].

Despite modern radiologic testing, idiopathic PD remains a medical diagnosis. A distal resting tremor of 3-6 Hz, stiffness, bradykinesia, and asymmetrical onset are the cardinal features necessary for diagnosis [15]. Radiologic advances have made it simpler to determine the etiology of Parkinson's disease and to identify idiopathic Parkinson's disease more precisely. Although CT and MRI scans of the head do not reveal any distinct patterns associated with Parkinson's disease, they may be used to rule out or confirm other disorders. There is, however, insufficient data to demonstrate that particular testing increase diagnosis accuracy [16]. According to new study, persons with Parkinson's 
disease have a more severe loss of smell than those with other kinds of parkinsonism [17]. Early on in the disease, clinicians should be aware that a clinical diagnosis of Parkinson's isn't very accurate. They should think about this when giving information to the patient and planning their care.

\section{Pharmacological Treatment}

Though the specific etiology of Parkinson's disease is unknown, therapy advances have been steady. The condition has no known cure, therefore therapies aim to control symptoms rather than prevent or reduce its course. The choice to restart therapy is based on patient desire, degree of non-motor and motor disability, and associated quality of life impairment. Occupation, age, and comorbidities all impact the date of treatment commencement [18]. The current medications may dramatically reduce symptoms [19]. There is no need to start taking medications for motor symptoms unless they significantly affect one's ability to operate and quality of life $[19,20]$. In the early stages of the condition, treatment may not be necessary if symptoms are mild and unobtrusive. Younger and older patients typically have different therapeutic objectives [21]. Patients who are younger may be more concerned with avoiding long-term treatment consequences whereas elderly patients may be more concerned with preserving daily abilities and maximizing function.

Levodopa, a dopamine precursor, is the gold standard for treating motor symptoms in PD. It is commonly used with an amino acid decarboxylase inhibitor (e.g. benserazide or carbidopa). It aims to improve motor symptoms [4]. In contrast to levodopa, there is a larger risk of side effects (e.g., poor impulse control, hallucinations, and excessive daytime sleepiness). Table 1 summarizes the possible advantages and risks of first-line PD medications.

Table 1. Typical Parkinson's disease medicines and their adverse effects

\begin{tabular}{|c|c|c|}
\hline Medication & Indication & Side effects \\
\hline $\begin{array}{l}\text { Anti-cholinergic } \\
\text { Benztropine }\end{array}$ & For symptomatic treatment of PD & $\begin{array}{l}\text { Dry eyes, hypotension, } \\
\text { constipation, urinary retention, dry } \\
\text { mouth, }\end{array}$ \\
\hline Carbidopa/Levodopa & $\begin{array}{l}\text { The most effective medicine for symptomatic Parkinson's } \\
\text { disease is levodopa; sustained release has no advantage over } \\
\text { immediate release for motor problems. }\end{array}$ & $\begin{array}{l}\text { Hypotension, } \quad \text { hallucinations, } \\
\text { nausea, dyskinesia, somnolence }\end{array}$ \\
\hline $\begin{array}{l}\text { Catechol O-methyltransferase } \\
\text { (COMT) inhibitors } \\
\text { Tolcapone } \\
\text { Entacapone }\end{array}$ & $\begin{array}{l}\text { The levodopa dosage may need to be lowered if dyskinesia } \\
\text { occurs. }\end{array}$ & $\begin{array}{l}\text { bright orange urine and diarrhea } \\
\text { Rare liver failure }\end{array}$ \\
\hline $\begin{array}{l}\text { Dopamine agonists } \\
\text { Bromocriptine } \\
\text { Pergolide } \\
\text { Pramipexole, Ropinirole } \\
\end{array}$ & $\begin{array}{l}\text { Useful for early and late disease } \\
\text { Used to treat parkinsonism and as an adjuvant to levodopa } \\
\text { therapy. } \\
\text { Useful for early disease of PD and motor fluctuations }\end{array}$ & $\begin{array}{l}\text { Headache, dizziness } \\
\text { Nausea somnolence, edema, } \\
\text { hallucinations } \\
\text { Hypotension, hallucinations }\end{array}$ \\
\hline $\begin{array}{l}\text { Monoamine oxidase-B (MAO-B) } \\
\text { inhibitors } \\
\text { Selegiline } \\
\text { Rasagiline }\end{array}$ & $\begin{array}{l}\text { As an adjuvant treatment for individuals with mild-moderate } \\
\text { PD with motor fluctuations. }\end{array}$ & $\begin{array}{l}\text { Nausea, insomnia } \\
\text { Dry mouth, hypotension, weight } \\
\text { loss }\end{array}$ \\
\hline $\begin{array}{l}\text { N-methyl-D-aspartate } \\
\text { receptor inhibitor } \\
\text { Amantadine }\end{array}$ & Useful in the treatment of stiffness and tremor & $\begin{array}{l}\text { Confusion, nausea, edema, } \\
\text { hypotension }\end{array}$ \\
\hline
\end{tabular}

Patients with Parkinson's disease respond best to a combination of levodopa and one of two enzyme inhibitors known as dopa decarboxylase inhibitors: carbidopa or benserazide. It is incorrect to withhold levodopa medication in hopes of delaying the development of motor irregularities such as peak dosage dyskinesia. A helpful alternative for those with moderate
Parkinson's disease is an MAO-B inhibitor, which is well tolerated and only takes one dose each day. Oral or topical dopamine agonists are also beneficial in moderate. Dopamine agonists may also cause excessive daytime sleepiness and hallucinations. Because dopamine agonists may produce nausea and dizziness, they should be started slowly. If a dopamine 
agonist or MAOB-B inhibitor is ineffective in controlling symptoms, levodopa, typically effective at modest doses, should be added (100 mg three times per day). Patients should be reassured about the safety and effectiveness of symptomatic therapy.

Not until motor symptoms impede function and quality of life should motor problems be medicated. Mild early-stage symptoms may not need treatment. The therapy objectives for young and senior patients typically vary [21]. The least dose of medicine is needed to treat symptoms, however numerous drugs are generally required, especially later [22]. Tables 2 summarize various therapies and drugs widely administered for non-motor symptoms.

Table 2. Commonly prescribed non-motor symptom treatments

\begin{tabular}{|l|l|l|}
\hline Symptom & Medication & Side effects \\
\hline Insomnia & Amitriptyline & $\begin{array}{l}\text { Dry eyes, constipation, } \\
\text { dry mouth, urinary } \\
\text { retention }\end{array}$ \\
\hline $\begin{array}{l}\text { Rapid eye } \\
\text { movement sleep } \\
\text { behaviour disorder }\end{array}$ & Clonazepam & Somnolence \\
\hline Constipation & Macrogol & $\begin{array}{l}\text { Nausea, diarrhoea, } \\
\text { abdominal discomfort }\end{array}$ \\
\hline Depression & Paroxetine & $\begin{array}{l}\text { Sedation, anorexia, } \\
\text { sexual dysfunction }\end{array}$ \\
\hline Psychosis & Quetiapine & Somnolence \\
\hline $\begin{array}{l}\text { Restless } \\
\text { syndrome }\end{array}$ & Pramipexole & $\begin{array}{l}\text { Nausea, hallucinations, } \\
\text { peripheral edema }\end{array}$ \\
\hline $\begin{array}{l}\text { Orthostatic } \\
\text { hypotension }\end{array}$ & Fludrocortisone & $\begin{array}{l}\text { Edema, hypertension, } \\
\text { hypokalaemia }\end{array}$ \\
\hline
\end{tabular}

There are promising early results for vaccines that reduce alpha-synuclein protein deposition. However, early research on the potential of the tyrosine kinase inhibitor nilotinib is conflicting [23].

\section{CONCLUSION}

Parkinson's disease treatment requires a lot of patience. Early identification and treatment of severe symptoms are challenging. The initial treatment should include early detection of Parkinson's disease core characteristics, diagnosis, and symptoms. The most effective treatment is levodopa. Many drugs are available to treat both motor and nonmotor disorders. More study is needed on under-researched PD medicines. Optimal management demands a diverse team approach.

\section{Acknowledgement: None}

\section{Conflict of Interest: None}

\section{Source of Funding: None}

\section{REFERENCES}

1. Rizek P, Kumar N, Jog MS. An update on the diagnosis and treatment of Parkinson disease. CMAJ 2016;188:1157-65.

2. Lewis SJ, Gangadharan S, Padmakumar CP. Parkinson's disease in the older patient. Clin Med 2016; 16: 376-8.

3. Jameson JL, Fauci AS, Kasper DL, Hauser SL, Longo DL, Loscalzo J. Harrison's principles of internal medicine. 12th ed. New York: McGraw-Hill Companies; 1991.

4. National Institute for Health and Care Excellence. Parkinson 's disease in adults: diagnosis and management. NICE guideline [NG71]. 2017.

5. Cheng H, Ulane CM \& Burke RE. Clinical progression in Parkinson's disease and the neurobiology of axons. Ann Neurol 2010;67(6): 715-725. doi: 10.1002/ana.21995.

6. Poewe W, Seppi K, Tanner CM, Halliday GM, Brundin P, Volkmann J, et al. Parkinson disease. Nat Rev Dis Primers. 2017; 3: 17013.

7. Peball M, Mahlknecht P, Werkmann M, Marini K, Murr F, Herzmann H, et $a l$. Prevalence and associated factors of sarcopenia and frailty in Parkinson's disease: a cross-sectional study. Gerontology 2019; 65: 216- 28

8. Nutt JG, Wooten GF. Clinical practice. Diagnosis and initial management of Parkinson's disease. $N$ Engl J Med. 2005; 353: 1021-7.

9. Jankovic J. Parkinson's disease: clinical features and diagnosis. J Neurol Neurosurg Psychiatry 2008;79:368-76.

10. Suchowersky O, Reich S, Perlmutter J, Zesiewicz T, Gronseth G, Weiner WJ; Quality Standards Subcommittee of the American Academy of Neurology. Practice parameter: diagnosis and prognosis of new onset Parkinson disease (an evidence-based review): report of the Quality Standards 
Subcommittee of the American Academy of Neurology. Neurology 2006;66:968-75.

11. Chaudhuri KR, Schapira AH. Non-motor symptoms of Parkinson's disease: dopaminergic pathophysiology and treatment. Lancet Neurol 2009;8:464-74

12. Chaudhuri KR, Healy DG, Schapira AH. Non-motor symptoms of Parkinson's disease: diagnosis and management. Lancet Neurol 2006;5:235-45.

13. Chan DK. Parkinson disease and its differentials: diagnoses made easy. Aust Fam Physician 2001; 30: 1053- 6.

14. Albanese A, Bonuccelli U, Brefel C, Chaudhuri KR, Colosimo C, Eichhorn $\mathrm{T}$, et al. Consensus statement on the role of acute dopaminergic challenge in Parkinson's disease. Mov Disord 2001; 16: 197- 201.

15. Italian Neurological Society, Italian Society of Clinical Neurophysiology. Guidelines for the treatment of Parkinson's disease 2002. The diagnosis of Parkinson's disease. Neurol Sci. 2003;(24 suppl 3):S157-64.

16. Agency for Healthcare Research and Quality. Diagnosis and treatment of Parkinson's disease: a systematic review of the literature. Accessed June 19, 2006, at: http://www.ahrq.gov/clinic/epcsums/park sum.htm.

17. Suchowersky O, Reich S, Perlmutter J, Zesiewicz T, Gronseth G, Weiner WJ. Practice parameter: diagnosis and prognosis of new onset Parkinson disease (an evidence-based review): report of the Quality Standards Subcommittee of the
American Academy of Neurology. Neurology. 2006;66:968-75.

18. de Bie RMA, Clarke CE, Espay AJ, Fox $\mathrm{SH}$, Lang AE. Initiation of pharmacological therapy in Parkinson's disease: When, why, and how. Lancet Neurol 2020;19(5):452-61. doi: 10.1016/S1474-4422(20)30036-3.

19. Hayes MW, Fung VSC, Kimber TE, O'Sullivan JD. Updates and advances in the treatment of Parkinson disease. Med $J$ Aust 2019; 211: 277- 83.

20. Kalia LV, Lang AE. Parkinson's disease. Lancet 2015; 386: 896-912.

21. Chen J, Fernandez H. Community and longterm care management of Parkinson's disease in the elderly. Drugs Aging 2007; 24: 663-80.

22. Klietz M, Greten S, Wegner F, Höglinger GU. Safety and tolerability of pharmacotherapies for Parkinson's disease in geriatric patients. Drugs Aging 2019; 36: 511- 30.

23. Pagan FL, Hebron ML, Wilmarth B, TorresYaghi Y, Lawler A, Mundel EE, et $a l$. Nilotinib effects on safety, tolerability, and potential biomarkers in Parkinson disease: a phase 2 randomized clinical trial. JAMA Neurol 2020; 77: 309- 17.

How to cite this article: Aiperi Almanbekova. Diagnosis and pharmacological management of Parkinson's disease: a review. Int J Health Sci Res. 2022; 12(2): 110-114. DOI: https://doi. org/10.52403/ijhsr.20220215 